\title{
De M@ZL-app: een eHealthapplicatie ter ondersteuning van de aanpak bij ziekteverzuim
}

\author{
I. A. M. Hogerwerf-van Dam · L. N. Douma · M. H. H. Hoogsteder
}

Published online: 14 april 2021

(c) Bohn Stafleu van Loghum is een imprint van Springer Media B.V., onderdeel van Springer Nature 2021

Samenvatting Inleiding: M@ZL is een integrale ziekteverzuimaanpak bij jongeren (12-23 jaar). De M@ZLapp is een webapplicatie die jongeren op het voortgezet onderwijs (12-18 jaar) meer regie en verantwoordelijkheid moet geven in het omgaan met ziekteverzuim. In een verkennend onderzoek keken we naar bevorderende en belemmerende factoren voor gebruik van de M@ZL-app, en naar mogelijkheden voor doorontwikkeling.

Methode: We organiseerden online focusgroepgesprekken met jongeren en met jeugdgezondheidszorg (JGZ)-professionals die ervaring hebben met ziekteverzuimconsulten op het voortgezet onderwijs.

Resultaten: Dertien jongeren en achttien JGZ-professionals deden mee aan ons onderzoek. Bijna alle deelnemers zien potentie in de M@ZL-app als aanvulling op ziekteverzuimconsulten. Ze denken dat de app het werken aan doelen kan ondersteunen, jongeren meer regie kan geven en contacten laagdrempeliger kan maken. Voor doorontwikkeling werden genoemd: maak een echte app, trek de doelgroep breder en maak gebruik van een belonings-/volgsysteem.

Conclusie: De M@ZL-app lijkt potentie te hebben. Om meer inzicht te krijgen in welke doelgroep en op welk moment in de ziekteverzuimaanpak de app het beste

Drs. I. A. M. Hogerwerf-van Dam ( $ه)$

GGD Amsterdam, Amsterdam, Nederland

ihogerwerf@ggd.amsterdam.nl

Dr. L. N. Douma

Academische Werkplaats 's Heeren Loo-VU, afdeling

Ontwikkelingspedagogiek, Vrije Universiteit Amsterdam, Amsterdam, Nederland

Dr. M. H. H. Hoogsteder

Academische Werkplaats Jeugd en Gezondheid, afdeling Public and Occupational Health, Amsterdam Public Health research institute, Amsterdam UMC locatie VUmc,

Amsterdam, Nederland ingezet kan worden zou onderzoek moeten worden gedaan waarin jongeren de app uitproberen. Cocreatie en intensieve training van JGZ-professionals lijkt raadzaam om inclusie in een pilotonderzoek te bevorderen.

Trefwoorden e-health · jongeren • jeugdgezondheidszorgprofessionals · ziekteverzuim • M@ZL

\section{Inleiding}

Wanneer ziekteverzuim onder jongeren op het voortgezet onderwijs (vo; 12-18-jarigen) niet goed wordt begeleid, is er een hoog risico op psychosociale, leefstijl- en motivatieproblemen, en vroegtijdig schoolverlaten [1, 2]. De integrale aanpak Medische Advisering Ziekgemelde Leerling (M@ZL - 'mazzel') kan helpen [3]. M@ZL zorgt voor meer samenwerking tussen de school, jeugdgezondheidszorg (JGZ)-professionals (jeugdartsen en jeugdverpleegkundigen) en leerplichtambtenaren. Jongeren met ziekteverzuim worden vroegtijdig gesignaleerd en begeleid. M@ZL is effectief gebleken in het verminderen van ziekteverzuim en wil jongeren de regie laten nemen, maar biedt hiervoor in de praktijk nog onvoldoende houvast [2, 4].

Een e-healthapplicatie ter ondersteuning van M@ZL kan meerwaarde hebben. E-health kan de communicatie en samenwerking tussen professionals verder bevorderen [5, 6]. Daarnaast kan e-health een preventieve functie en breed bereik hebben, toegankelijk zijn en mogelijkheden bieden voor maatwerk [6-9]. Ook kan e-health ingezet worden voor begeleiding op afstand en gedragsverandering stimuleren [7]. Daarom is de M@ZL-app ontwikkeld (zie fig. 1), een webapplicatie ontworpen na een behoeftenonderzoek onder jongeren, professionals uit het onderwijs en JGZ-professionals $[10,11]$. Doel van de app is jongeren te 


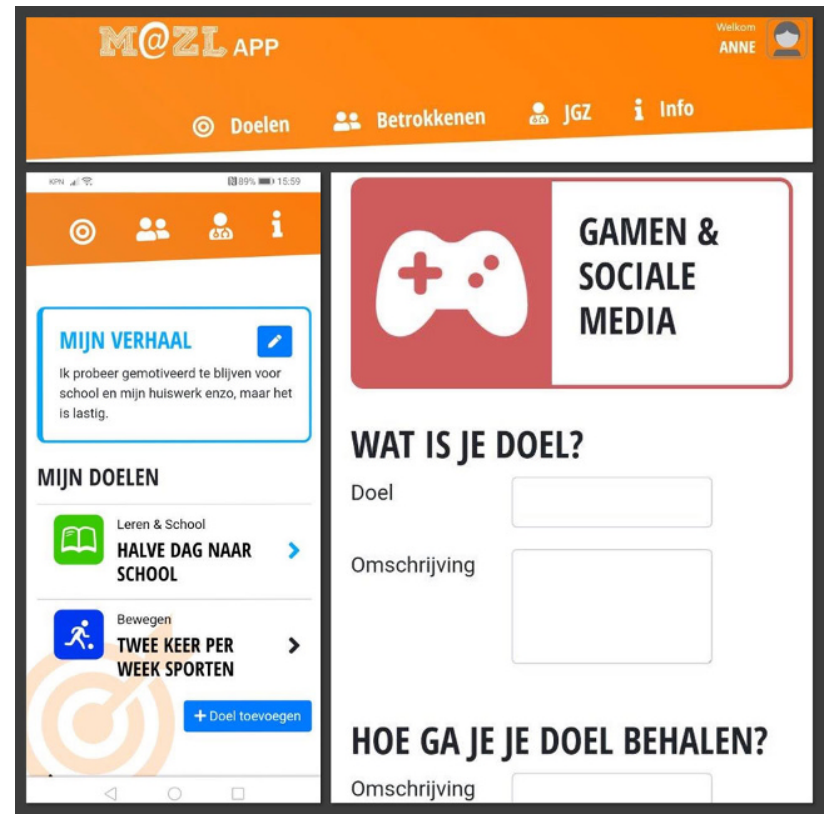

Figuur 1 De M@ZL-app

ondersteunen bij het omgaan met hun ziekteverzuim, zodat ze sneller terugkeren naar school. De belangrijkste functionaliteiten van de app zijn het werken met zelfgeformuleerde doelen, het erbij betrekken van het sociale netwerk (zoals familie, vrienden en mentor), het onderhouden van laagdrempelig contact met de JGZ-professional en het geven van informatie over ziekteverzuim [10].

Voor doorontwikkeling en een bredere implementatie van de M@ZL-app is inzicht in de gebruikerservaring essentieel, zowel van jongeren als JGZ-professionals [6, 9, 12, 13]. Van oktober 2019 tot maart 2020 werd de app in drie GGD-regio's in pilotverband beschikbaar gesteld. Helaas is deze pilot niet van de grond gekomen. JGZ-professionals hadden onvoldoende mogelijkheden om de app in ziekteverzuimconsulten aan jongeren aan te bieden. Dit hing samen met een personeelstekort, hoge werkdruk, krap geplande ziekteverzuimconsulten en onvoldoende tijd om de app goed te leren hanteren.

Doordat de M@ZL-app niet gebruikt is, verschoof de focus van ons onderzoek van gebruikerservaringen naar een verkennend onderzoek van de huidige appversie. We onderzochten welke bevorderende en belemmerende factoren jongeren en JGZ-professionals ervaren bij het gebruik en de implementatie van de app, wie zij als doelgroep beschouwen en welke doorontwikkelingsmogelijkheden ze zien.

\section{Methode}

\section{Onderzoekspopulatie}

Drie Flevolandse scholen zijn benaderd om jongeren voor focusgroepen te werven. Verder namen drie GGD-regio's (Amsterdam (A), West-Brabant (B) en Flevoland (C)) deel. Via een coördinator per regio werden dertig JGZ-professionals met ervaring in ziekteverzuimconsulten op het vo uitgenodigd voor het onderzoek. Jongeren en JGZ-professionals meldden zichzelf aan voor ons onderzoek. Geen van de deelnemers heeft daadwerkelijk met de M@ZL-app gewerkt.

\section{Opzet}

Om feedback van zo veel mogelijk deelnemers te krijgen en hen tot discussie te stimuleren werden in de periode april-mei 2020 voor jongeren en JGZ-professionals apart online focusgroepgesprekken (vanwege COVID-19) georganiseerd. De focusgroepgesprekken vonden plaats op Zoom en Microsoft Teams en werden uitgevoerd volgens een draaiboek gebaseerd op literatuuronderzoek en de onderzoeksvragen. De gesprekken met jongeren en JGZ-professionals werden geleid door respectievelijk één (LD) en twee onderzoekers (IH en LD). Na een introductiefilmpje over de M@ZL-app vond een groepsgesprek plaats. Ook werden enkele achtergrondkenmerken uitgevraagd.

\section{Ethische toestemming}

Het onderzoek is onder dossiernummer 2019.142 beoordeeld door de METc van Amsterdam UMC locatie VUmc en niet-WMO-plichtig bevonden. Deelnemers kregen vooraf een informatiebrief en tekenden een toestemmingsverklaring voor volledige geluidsopname van de gesprekken, gepseudonimiseerde verwerking en geanonimiseerd gebruik van de data. Voor deelnemers onder 16 jaar gaven ook ouders toestemming.

\section{Analyse}

De geluidsopnamen van de gesprekken zijn volledig getranscribeerd. De jongerendata werden geanalyseerd in Atlas.ti8 (door LD), de data van de JGZ-professionals in MAXQDA2020PRO (door IH). De analyse is gestart nadat alle data verzameld waren.

Op basis van literatuur en de onderzoeksvragen is een raamwerk opgesteld met relevante basisthema's (bijvoorbeeld attitude, eigen regie, aansluiting bij M@ZL), dat als uitgangspunt diende voor de eerste stappen van de data-analyse (open coderen en axiaal coderen). Ten slotte is er selectief gecodeerd om de samenhang en relevantie van de thema's te bepalen en zijn er vier hoofdonderwerpen geïdentificeerd: 1) bevorderende factoren; 2) belemmerende factoren; 3) doelgroep M@ZL-app; 4) mogelijkheden voor doorontwikkeling. De onderzoekers hebben elke fase van coderen samen besproken, totdat consensus over de analyse bereikt werd. 


\section{Resultaten}

\section{Onderzoekspopulatie}

Er vonden één focusgroepgesprek $(n=7)$ en drie interviews $(n=2, n=1, n=1)$ plaats, met in totaal elf jongeren. Twee jongeren (jongens, 16 en 23 jaar) testten de M@ZL-app in de ontwerpfase. Zij hadden ervaring met ziekteverzuim op het vo en met appontwikkeling, waardoor hun feedback toegevoegde waarde had en is meegenomen in de analyse.

Van de dertien jongeren waren er negen man, de gemiddelde leeftijd was 15 jaar (spreiding 13-23), de opleiding was divers (vier vmbo, acht havo, één vwo), zeven volgden speciaal onderwijs en drie hadden ervaring met frequent of langdurig ziekteverzuim.

Verspreid over drie focusgroepen ( $n=5, n=4, n=4)$ in twee regio's hebben dertien JGZ-professionals deelgenomen. Daarnaast is in de derde regio één JGZbeleidsmedewerker geïnterviewd. Vier JGZ-professionals hebben per e-mail feedback gegeven.

Van de achttien deelnemende JGZ-professionals waren er zeventien vrouw; zestien waren werkzaam als jeugdarts, één als jeugdverpleegkundige en één als beleidsmedewerker. Het aantal jaren werkzaam in de JGZ varieerde van $<5$ jaar tot $>25$ jaar en dertien werkten met een ziekteverzuimaanpak zoals M@ZL (de meesten gedurende 4-6 jaar) (onbekend voor vijf JGZ-professionals).

\section{Bevorderende factoren}

Alle jongeren en JGZ-professionals zijn positief over het idee achter de M@ZL-app en de basisfuncties in de huidige webapplicatie. De app ziet er volgens hen netjes en overzichtelijk uit, oogt compleet en lijkt vrij eenvoudig in gebruik. Het lijkt iedereen prettig dat het contact tussen jongere, JGZ en alle andere betrokkenen op één plek plaatsvindt, namelijk de app. Dit voelt laagdrempeliger en sneller dan bijvoorbeeld e-mail of bellen.

De samenvatting voor mij is: het ziet er goed uit,

en $i k$ denk dat ik er ook wel wat mee kan (jongen, 13, vmbo).

Alle jongeren vinden het motiverend om te werken met doelen en een streefdatum. Verschillende van hen geven aan dat de motivatie in het begin vaak het grootst is. Om dit vast te houden is blijvend aanmoedigen, complimenteren en belonen nodig. Alle jongeren vinden dat dit zowel vanuit mensen in hun omgeving moet gebeuren, als vanuit ingebouwde functies van de M@ZL-app (stickers, GIF'jes, winning streaks). De meeste jongeren vinden het motiverend om de eigen voortgang te kunnen zien. Deze functie moet wel uitgezet kunnen worden.

De meeste JGZ-professionals vinden dat de M@ZLapp een goed overzicht kan geven van betrokken hulpverleners en het contact tussen alle hulpverleners kan faciliteren, met medeweten van de jongere. Ze vinden het belangrijk dat de app met zo min mogelijk handelingen te gebruiken is.

\section{Belemmerende factoren}

Jongeren noemen niet veel belemmerende factoren om met de M@ZL-app te gaan werken. Verschillende jongeren zeggen dat ze niet zo snel met een webapplicatie zouden werken. Dit voelt minder comfortabel en biedt minder gebruiksgemak dan een echte app. Enkelen denken dat met de M@ZL-app werken lastiger is wanneer je meer behoefte hebt aan persoonlijk contact.

JGZ-professionals voorzien meer belemmeringen. De meesten vonden de webversie minder gemakkelijk ogen dan een echte app. Daarnaast menen JGZ-professionals dat het tijd kost om te wennen aan nieuwe werkwijzen en digitale middelen.

Je ziet er eigenlijk enorm tegenop. Je moet je inloggen, wachtwoorden en noem maar op. En op een gegeven moment, zo werkt het met al dit soort digitale zaken, weet je het gewoon en dan gaat het tien keer zo snel (JGZ-professional, GGD B).

Alle JGZ-professionals denken dat de huidige duur van een ziekteverzuimconsult onvoldoende tijd biedt om de M@ZL-app goed met jongeren te kunnen bespreken.

\section{Doelgroep van de M@ZL-app}

Alle jongeren en JGZ-professionals vinden de eigen motivatie van jongeren om aan hun situatie te werken belangrijk. Beide groepen denken dat de M@ZLapp breder ingezet kan worden dan alleen voor leerlingen met veel verzuim. Ze denken aan doelen gerelateerd aan ziekteverzuim en aan ander functioneren (bijvoorbeeld plannen, gezonde leefstijl, verslavingen, depressie).

lk denk dat deze app ook handig kan zijn voor mensen die niet te maken hebben met ziekteverzuim (jongen, 15, havo).

Jongeren en JGZ-professionals vinden dat de M@ZL-app in dat geval niet alleen door de JGZ aangeboden moet worden, maar ook door bijvoorbeeld de mentor of leerkracht vanuit school.

JGZ-professionals vinden het lastig om in te schatten wie de specifieke doelgroep voor de app vormt. De meeste JGZ-professionals denken dat de app al geschikt is voor basisschoolleerlingen vanaf ongeveer 10 jaar en voor leerlingen op het vo, mits ze gemotiveerd zijn en met doelen willen/kunnen werken. Jongeren geven aan dat de app ook gebruikt kan worden door jongeren tot 25 jaar. JGZ-professionals hebben tegenstrijdige meningen over de doelgroep jongeren met complexe problematiek. Sommigen denken dat zij minder gemotiveerd zijn voor werken aan doelen 
in de app, omdat JGZ-professionals in hun gesprekken met hen vaker weerstand ervaren. Ook zou de app te belastend kunnen zijn. Anderen denken dat de app voor deze doelgroep juist een eerste stap richting herstel kan ondersteunen of kan helpen bij het in kaart brengen van problematiek.

\section{Mogelijkheden voor doorontwikkeling}

Jongeren vinden dat de M@ZL-app moet lijken op downloadbare apps die ze dagelijks gebruiken, waarin je vanuit een hoofdscherm swipet naar andere onderdelen, en waar filmpjes en documenten ingebouwd zijn. Jongeren vinden het belangrijk dat het systeem voor belonen en het volgen van de voortgang verder uitgebouwd wordt. Een goede instructie (tutorial) voor henzelf en de mensen die ze erbij betrekken is belangrijk. Jongeren willen betrokken zijn bij de doorontwikkeling van de M@ZL-app, omdat zij ermee moeten werken.

Bijna alle JGZ-professionals adviseren eveneens een downloadbare app te maken.

\section{Ik vind dat het heel erg aansluit bij de belevings- wereld van jongeren. Het zou denk ik alleen super zijn als het echt een app is (JGZ-professional, GGD A).}

Wanneer de app toegankelijk is voor meerdere hulpverleners kan deze dubbele administratie en communicatie ondervangen. JGZ-professionals adviseren een selecte groep jeugdartsen en/of aios te betrekken bij de ontwikkelfase en intensief te trainen in het gebruik van de app, zodat ze er echt goed mee kunnen werken.

\section{Beschouwing}

Jongeren en JGZ-professionals zijn positief over het idee van de M@ZL-app en vinden dat deze potentie heeft. Ze denken dat de app jongeren kan ondersteunen bij het omgaan met ziekteverzuim doordat deze het werken aan doelen ondersteunt, jongeren meer regie geeft en het contact tussen jongere, JGZ-professionals en andere betrokkenen laagdrempeliger kan maken. Dit sluit aan bij wensen en behoeften die naar voren kwamen bij een verkenning vooraf [11].

De resultaten raken aan belangrijke aspecten van de aanpak van ziekteverzuim [14], preventie in brede zin $[15,16]$ en ontwikkeling en implementatie van nieuwe digitale interventies [13, 17]. Zicht hierop draagt bij aan het succes van een vervolgpilot met de M@ZL-app in de praktijk. Wanneer de huidige M@ZL-webapplicatie wordt veranderd in een echte, downloadbare app zullen de gebruiksvriendelijkheid en het vertrouwen in de app volgens jongeren en JGZprofessionals toenemen.

JGZ-professionals denken dat het werken aan doelen voor iedere gemotiveerde jongere geschikt is. Ze verschillen echter van mening over de mate waarin jongeren gemotiveerd zullen zijn of te motiveren zijn. Dit verschil in visie onder JGZ-professionals maakt het moeilijker om te bepalen welke doelgroep (het meest) baat kan hebben bij de M@ZL-app. Jongeren vinden motivatie ook belangrijk. Ze denken dat de app motiverend kan werken, zeker wanneer het beloningssysteem verder uitgewerkt wordt en jongeren hun eigen voortgang kunnen volgen. Jongeren vinden het belangrijk dat hun omgeving hen kan motiveren, zowel via de M@ZL-app als daarbuiten.

Jongeren en JGZ-professionals denken dat de M@ZL-app breder ingezet kan worden dan oorspronkelijk beoogd, zowel qua leeftijdsgroep als problematiek. De app zou voor jongeren vanaf 10 jaar tot op het mbo (23 jaar) geschikt kunnen zijn, en behalve voor ziekteverzuim ook voor leefstijlproblematiek of verslavingen. In de huidige M@ZL-app is het al mogelijk om voor deze onderwerpen doelen te maken, vanuit de gedachte dat ziekteverzuim kan samenhangen met problemen op diverse gebieden [14]. Een bredere inzet van de app kan preventie bij (leefstijl)problemen versterken voordat ziekteverzuim de ontwikkeling bedreigt [18]. Meer zicht is nodig op welk moment en voor welke problematiek de app het best ingezet kan worden. Het lijkt raadzaam om na te gaan of de app deel kan worden van bestaande e-healthapplicaties of andere tools op dit gebied.

Een beperking van ons onderzoek is het ontbreken van echte gebruikerservaringen en het kleine aantal jongeren in ons onderzoek dat ervaring heeft met frequent of langdurig ziekteverzuim. Hierdoor weten we niet of jongeren die op ziekteverzuimconsulten komen daadwerkelijk baat zullen hebben bij de M@ZLapp. Ook was er sprake van een relatief kleine groep deelnemers. Voor online focusgroepgesprekken zijn acht tot tien deelnemers wenselijk. Dat aantal werd niet gehaald, mede door de COVID-19-omstandigheden en hoge werkdruk bij JGZ-professionals. Desondanks hebben we gevarieerde input verkregen van zowel jongeren als JGZ-professionals, die kan helpen bij de doorontwikkeling van de M@ZL-app. De data zijn voornamelijk verzameld en geanalyseerd door een van de onderzoekers. Volledige codering door een tweede onderzoeker was niet mogelijk, maar de codering gebeurde secuur en systematisch, met continue afstemming tussen de onderzoekers. Een andere beperking is dat deelnemers zich zelf voor het onderzoek hebben aangemeld. Jongeren en JGZ-professionals die minder positief zijn over e-healthinnovaties/-applicaties hebben mogelijk niet meegedaan.

\section{Aanbevelingen}

Voor de doorontwikkeling van de M@ZL-app is het wenselijk dat de huidige verkennende inzichten verwerkt worden en er een (nieuw) pilotonderzoek komt waarin jongeren en professionals een echte, downloadbare app uitproberen. Zo krijgen we meer zicht op welke jongeren - en op welk moment - baat heb- 
ben bij de M@ZL-app. Hierbij kan overwogen worden om niet de JGZ-professional het beheer over de app te geven, maar de mentor of leerkracht. Voor de doorontwikkeling is het belangrijk dat eindgebruikers - jongeren, JGZ-professionals en anderen - er actief bij betrokken blijven, om aan te sluiten bij hun leefwereld en behoeften, bijvoorbeeld in de vorm van cocreatie $[13,19,20]$. Een kernteam met jeugdartsen en/of aios zou intensief getraind kunnen worden in het gebruik van de M@ZL-app en de werving van jongeren. Daarnaast kunnen ze meedenken over de vraag hoe met belemmerende factoren kan worden omgegaan, zoals de duur van ziekteverzuimconsulten en werkdruk.

De literatuur laat zien dat implementatie van e-healthapplicaties succesvoller is wanneer deze de bestaande werkwijze efficiënter maken en er aandacht is voor verschuivingen in de verantwoordelijkheden en rol van de professional. Er moet voldoende tijd zijn voor training in het gebruik van e-healthapplicaties en deze moeten gebruiksvriendelijk, betrouwbaar, goed beveiligd en toegankelijk zijn. Professionals die een positieve attitude ten aanzien van e-health hebben, computervaardig zijn én motivatie tot verandering hebben, vergroten de kans op succesvolle implementatie van e-healthapplicaties $[6,9,17]$.

\section{Literatuur}

1. Freudenberg N, Ruglis J. Reframing school dropout as a public health issue. Prev Chronic Dis. 2007;4:1-11.

2. Vanneste YTM, Feron FJM, Mook MAW van, et al. Towards a better understanding of sickness absence in adolescence: a qualitative study among Dutch intermediate vocational education students. Bio Med Res Int. 2017;2017:1064307.

3. Vanneste YTM, Rots-de Vries MC, Van de Goor LAM, et al. Medische Advisering Ziekgemelde leerling door de jeugdarts (M@ZL); ontwikkeling van een interventie. TSG Tijdschr Gezondheidswet. 2012;90(7):412-9.

4. Vanneste YTM, Mathijssen JJ, Goor IA van de, et al. Addressing medical absenteeism in pre-vocational secondary students: effectiveness of a public health intervention, using a quasi-experimental design. BMC Publ Heal. 2016;16(1):1107.

5. Oh H, Rizo C, Enkin M, Jadad A. What is eHealth (3): a systematic review of published definitions. J Med Internet Res. 2005;7(1):e1.

6. Kay M, Santos J, Takane M. mHealth: new horizons for health through mobile technologies. band 64 . Geneva: WHO;2011:66-71.

7. Bakker D, Kazantzis N, Rickwood D, et al. Mental health smartphone apps: review and evidence-based recommendations for future developments. JMIR Ment Health. 2016;3(1):e7.
8. Whitehead L, Seaton P. The effectiveness of self-management mobile phone and tablet apps in long-term condition management: a systematic review. J Med Internet Res. 2016;18(5):e97.

9. Commission E. Green paper on mobile health ('mHealth'). Brussels: European Commission; 2014.

10. Douma L, Roelofsen G, Hoogsteder M. M@ZL app: ontwikkeling en evaluatie van een verzuimapp voor jongeren. 2020. https://www.zonmw.nl/fileadmin/zonmw/ documenten/Jeugd/Versterking_uitvoeringspraktijk_jgz/ 736300012_M\%40ZL_app/2020-12_Eindrapport_M\%40ZL_ app_project.pdf. Geraadpleegd op: 26 nov 2020.

11. Hoogsteder MH, Douma LN, Eskens CG, et al. Professionals and students positive about an online supportive application preventing school absence and fostering reintegration. A concept mapping study. JMIR Prepr. 2020;24659. under review.

12. ZonMw Jeugd. Tips voor succesvolle inclusie in jeugdonderzoek. Den Haag: ZonMw Jeugd; 2020.

13. Whitehouse SR, Lam PY, Balka E, et al. Co-creation with TickiT: designing and evaluating a clinical ehealth platform for youth. Jmir Res Protoc. 2013;2(2):e42.

14. Sleeuwen W van, Heyne D. Schoolverzuim aanpakken: een wetenschappelijke onderbouwing. 2020. https://www. nji.nl/nl/Kennis/Dossier/Voortijdig-schoolverlaten-enverzuim/333639-Publicaties-NJi. Geraadpleegd op: 30 nov 2020.

15. Trimbos-instituut. Geluk onder Druk? Onderzoek naar het mentaal welbevinden van jongeren in Nederland. Den Haag: UNICEF Netherlands; 2020.

16. SER. Zorg voor de toekomst. Over de toekomstbestendigheid van de zorg. Den Haag: Sociaal-Economische Raad; 2020.

17. Ross J, Stevenson RL, Murray E. Factors that influence the implementation of e-health: a systematic review of systematic reviews (an update). Implement Sci. 2016;11:146.

18. Hawkrigg S, Payne DN. Prolonged school non-attendance in adolescence: a practical approach. Arch Dis Child. 2014;99(10):954-7.

19. O'Hern MS, Rindfleisch A. Customer co-creation: a typology and research agenda. In: Malhotra NK, redactie. Review of marketing research. Abingdon: Taylor \& Francis Group; 2010.

20. Frankwatching. Co-creatie: zo organiseer je een effectieve sessie. 2019. https://www.frankwatching.com/archive/ 2019/05/07/co-creatie-effectieve-sessie/. Geraadpleegd op: $1 \operatorname{dec} 2020$.

I.A.M. Hogerwerf-van Dam, jeugdarts KNMG, aios arts Maatschappij \& Gezondheid

Dr. L.N. Douma, sociaal psycholoog, postdoc onderzoeker

Dr. M.H.H. Hoogsteder, psycholoog, senior onderzoeker/ coördinator 